\title{
Cellulosic Paper-Based Membrane for Oil-Water Separation Enabled by Papermaking and in-Situ Gelation
}

\section{Decheng Gao}

South China University of Technology

\section{Yucheng Feng}

South China University of Technology

\section{Xiao Zhang}

South China University of Technology

\section{Shuying Wu}

South China University of Technology

Fei Yang ( $\nabla$ yangfei@scut.edu.cn )

South China University of Technology https://orcid.org/0000-0002-8122-422X

\section{Research Article}

Keywords: Biodegradable materials, Pulp refining, Oil-water separation, Cellulose, Papermaking

Posted Date: December 14th, 2021

DOI: https://doi.org/10.21203/rs.3.rs-1079247/v1

License: (c) (1) This work is licensed under a Creative Commons Attribution 4.0 International License. Read Full License

Version of Record: A version of this preprint was published at Cellulose on March 31st, 2022. See the published version at https://doi.org/10.1007/s10570-022-04537-2. 


\section{Abstract}

While has obvious scientific significance, the oil-water separation membranes are argued at production and disuse, mainly ascribed to the complex processes and non-biodegradation. Papermaking has great potential in the field of oil/water separation. The pulp refining of papermaking can improve the properties of pulp to improve the properties of paper substrate, which play an important role in oil-water separation. Due to the separation process was conducted under water, the wet strength of paper-based membrane was improved by micro-dissolved and in-situ gelation. The strength, oil-water separation efficiency and flux of membranes were explored under different beating degrees and regenerated conditions. The separation for oil-water emulsion of membranes can keep more than $98.5 \%$, and the flux can be adjusted by pulp refining and in-situ gelation. The membranes are expected to be a low-cost, high-efficient for oily wastewater purification. This work demonstrates a new idea for the development of oil-water separation and papermaking, which provides a feasible strategy for large scale production of fully biodegradable oilwater separation membrane.

\section{Introduction}

The rapid development of industry leads to the increasing use of petroleum products which produce tremendous oily wastewater pollution during the transportation and use. The industrial effluent results in severe ecological environment problems and damages human health(Cai, Zhu, Chen \& Zhang, 2019; Chen et al., 2016; Dalton \& Jin, 2010). Therefore, the urgency of finding oil-water separation materials for effective treatment of oily wastewater attracted many researchers (Ivshina et al., 2015; Li, Zhou \& Luo, 2017). The oil in oily wastewater is mainly three types, the floating oil, the dispersed oil and the emulsified oil (Chakrabarty, Ghoshal \& Purkait, 2008). The floating oil and dispersed oil are easily separated.

However, the emulsified oil is relatively difficult to separate. Comparing with the traditional methods of oilwater separation, membrane separation is more convenient and feasible (M. Cheryana, 1998; Zhu, Wang, Jiang \& Jin, 2014). Especially the membranes with special wettability are common in the field of oil-water separation (Ahmad, Majid \& Ooi, 2011; Feng \& Jiang, 2006; Wang, Liang, Guo \& Liu, 2014). Among them, the membranes with superhydrophilicity and underwater superoleophobicity properties have wide potential application due to the excellent underwater oil repellence and efficient oil-water separation performance (Ao et al., 2018; Hu et al., 2016; Zhang et al., 2018). However, most materials of oil-water separation are composed of non-renewable or non-degradable materials, which are apt to cause secondary pollution to the environment (Anis, Lalia, Lesimple, Hashaikeh \& Hilal, 2021; Ao et al., 2020; Gu et al., 2017). Thus, it has significant meaning for the development of environment-friendly materials.

Cellulose is the best material for oil-water separation with both renewability and degradability from an environmental point of view (Huang et al., 2021; Xie et al., 2019; Xu et al., 2021). However, most of them focus on superoleophobicity materials, which can be easily fouled by oily wastewater and even blocked(Chu, Feng \& Seeger, 2015; Zhao et al., 2021). The oil fouling is hard to wash off owing to the high viscosity, so that the waste membranes will bring the secondary pollution to the environment and shorten the service life of these materials(Lin et al., 2010). The application of oil-water separation materials with 
superhydrophilicity and underwater superoleophobicity properties has attracted more and more attention in recent years. These materials can form a hydration layer to separate oil-water mixtures (Li, Wang, Huang, Pan \& Zhao, 2018; Rana \& Matsuura, 2010; Yang, Yan, Ma, Bai \& Shao, 2019). This group of materials can improve the shortcomings in the separation process, especially on the issue of anti-oil fouling(Yang, Sun, Pal, Bai \& Shao, 2018). Ao et al (Ao et al., 2018). fabricated an oil-water separation membrane which is constructed by dipping the metallic mesh in the cellulose solution. Nevertheless, the disused metallic mess would cause secondary pollution.

As the earliest industry using cellulose systematically, papermaking offers the advantages of wellestablished technologies, stable equipment and rapid development (Gharehkhani et al., 2015; Hou, Yang, Liu, Liu, Hong \& Zhang, 2011). Therefore, it is a feasible method to prepare the substrate of cellulose separation membrane by papermaking (Sehaqui, Zhou, Ikkala \& Berglund, 2011). Pulp refining as an important link of papermaking can improve the performance of paper by refining pulp fibers to an ideal level, increasing the specific surface area of fibers and the connectivity of cellulose frame structure within paper (Afra, Yousefi, Hadilam \& Nishino, 2013). Through this process, it can cause a variety of changes in cellulose fibers such as internal fibrillation, external fibrillation, fiber shortening or cutting, and fines formation by peeling-off the cellulose fibers (Banavath, Bhardwaj \& Ray, 2011). With the occurrence of pulp refining, the fibers explore more hydroxyl than untreated pulp and the paper with refined pulp is denser than that of unrefined pulp (Yousefi, Faezipour \& Nishino, 2011). With the increase of hydroxyl, paper can greatly improve the water-absorbing properties. Meanwhile, the pore structure in the paper structure shrinks and the paper is denser, the barrier properties of paper have been improved (Xi, Lou, Jiang, Fang \& Wu, 2021). The paper can absorb water immediately to form a hydration layer, which can repel oil. However, it is necessary to find a way to stabilize the structure of paper in water, or the paper is easy to loosen because of the low wet strength.

Cellulosic self-reinforced material is a novel environmentally material (Nishino, Matsuda \& Hirao, 2004). which can be prepared by two methods: mixing cellulose fibers with cellulose solution or immersing the cellulose fibers into the cellulose solvent to dissolve the cellulose fibers partially to improve the strength of materials. (Shibata, Teramoto, Nakamura \& Saitoh, 2013). (Piltonen, Hildebrandt, Westerlind, Valkama, Tervahartiala \& Illikainen, 2016). Thus, cellulosic materials have an increasing of mechanical properties by pretreating it with cellulose solvent.

Herein, a cellulosic paper-based membrane for continuous oil-water separation was prepared by papermaking and in-situ gelation. It is noteworthy that pulp refining played an essential role in the oilwater separation process. The narrowed pore size and the increased water retention of paper by pulp refining helped to form a hydration layer to repel oil droplets. Meanwhile, the gelation structure by in-situ gelation and the multilayer cellulose frame by papermaking formed an interpenetrating network to enhance the strength of membrane. In addition, we explored the effects of different regeneration solutions to the properties of membranes, such as water, ethanol, sulphate solution and acetic acid.

\section{Materials And Methods}




\subsection{Materials}

Bleached softwood pulp was provided by Shun Pu Paper Co., Ltd (Zhejiang, China). Its polymerization (DP) was measured to 846 by viscosity measurements. $\mathrm{NaOH}$, toluene and xylene were supplied by Guangzhou Chemical Reagent Company(Guangzhou, China). Urea was supplied by Guangdong Guanghua Sci-Tech Co., LTD (Guangzhou, China). Acetic acid glacial, sodium sulfate, petroleum ether and liquid paraffin were supplied by Qiangsheng Functional Chemical Co., LTD (Jiangsu, China).,Nhexane and Tween-80 were supplied by Kermio Chemical Reagent Co., LTD (Guangzhou, China). Pump oil is a commercial product.

\subsection{Preparation of membranes}

Soft wood pulp was refined to $20^{\circ} \mathrm{SR}, 25^{\circ} \mathrm{SR}, 30^{\circ} \mathrm{SR}, 35^{\circ} \mathrm{SR}, 40^{\circ} \mathrm{SR}, 45^{\circ} \mathrm{SR}, 50^{\circ} \mathrm{SR}$ by using PFI refiner (Mark V1, HAMJERN MASKIN 621, Norway) according to ISO 5264-2:2002, unrefined pulp was $10^{\circ} \mathrm{SR}$. The paper substrates were prepared by Paper sheet former (MESSMER 255, USA) with an average grammage of $80 \mathrm{~g} / \mathrm{m}^{2}$. The substrates were dried at $105^{\circ} \mathrm{C}(10 \mathrm{~min})$. And stored at $25^{\circ} \mathrm{C}$ and $50 \% \mathrm{RH}$ for $24 \mathrm{~h}$ or more. The paper-based membranes were prepared by partial dissolving the paper substrates (Liquid absorption, $400 \pm 10 \mathrm{~g} / \mathrm{m}^{2}$ ) with $\mathrm{NaOH} /$ urea solvent $\left(\mathrm{w} / \mathrm{w}, 8: 12\right.$ ) at $-11^{\circ} \mathrm{C}$ for $15 \mathrm{~min}$. Then put them into regeneration solution for $15 \mathrm{~min}$, washed them with water, and dried at $90^{\circ} \mathrm{C}(0.1 \mathrm{MPa})$.

\subsection{Oil-water separation process}

The emulsion was prepared by homogenizing toluene and water at $1 / 99(\mathrm{v} / \mathrm{v})$ with $1 \mathrm{wt} \%$ tween-80 as surfactant-stabilized at 7000rpm for $10 \mathrm{~min}$ (Ao et al., 2020). The separation process is under the gravity of emulsions. The separation efficiency $(R)$ of emulsion was determined by measuring the volume concentration of toluene in the solution before and after separation by UV-vis spectra, and calculating according to the Equation:

$$
R=\left(1-\frac{\mathrm{Cp}}{\mathrm{Co}}\right) \times 100 \%
$$

Where $\mathrm{C}_{\mathrm{p}}$ is the volume concentration of emulsion and $\mathrm{C}_{0}$ is the volume concentration of filtrate. The flux (J) $\left(\mathrm{L} \cdot \mathrm{m}^{-2} \cdot \mathrm{h}^{-1}\right)$ was expressed by the Equation below:

$$
J=\frac{v}{S \times t}
$$

Where $v(L)$ is the volume of filtrate, $t(h)$ is the separating time and $S\left(\mathrm{~m}^{2}\right)$ is the effective area of membranes.

\subsection{Characterization}

The scanning electron microscope (SEM; S-3700N, Hitachi, L td., Tokyo, Japan) was used to carry out the SEM observations of membranes. The tensile index was tested by L\&W Tensile Strength Tester (L\&W CE062, Lorentzen\&Wettre, Sweden) according to ISO 1924/1-1983 (Dry tensile index) and ISO 3781- 
1983(Wet tensile index), and the burst index was tested by L\&W Burst Tester (L\&W CE180, Lorentzen\&Wettre, Sweden) according to ISO 2758-1983(Dry burst index) and ISO 3689-1983(Wet burse index).

\subsection{The pore diameter calculation}

The pore diameter was tested by mercury intrusion method by mercury porosimeter (AutoPore IV 9520). The range is $3 \mathrm{~nm}-1000 \mu \mathrm{m}$, the maximum is $414 \mathrm{Mpa}$. The length and width of sample is both allowed less than $1.5 \mathrm{~cm}$. The pore size was calculated according to(Moura, Ferreira \& Figueiredo, 2005):

$$
d=\frac{-4 \gamma \cos \theta}{\mathrm{p}}
$$

Where $\gamma$ is the surface tension; $\theta$ is the contact angel, $\theta=130^{\circ} ; \mathrm{d}$ is the pore diameter; $\mathrm{p}$ is the applied pressure.

\section{Results And Discussion}

\subsection{Morphology and properties of membranes}

The membranes were prepared by papermaking and in-situ gelation. Fig. 1 shows the route for the preparation of membranes. Low porosity and adhesion effect of materials contributed to the strength and barrier performance of membrane. Papermaking started from the paper substrates. The density and barrier of paper-based membranes were enhanced by improving the properties of pulp through pulp refining. And papermaking provided the fibers network for membranes. With the occurrence of gelatinization by pretreated in $\mathrm{NaOH} /$ urea, the fibers in paper substrate were covered by gel. The gelation structure could endow an underwater strength stability for membranes. And the stability was reflected by the enhancement of wet strength of the membranes.

The SEM images showed the microstructure changes of the surface and cross section of untreated paper sheets and membranes in Fig.2. The paper substrates with unrefined pulp ( $\left.10^{\circ} \mathrm{SR}\right)$ were porous and loosen (Fig. $2 \mathrm{a}$ ). In contrast, the paper substrates formed by $35^{\circ} \mathrm{SR}$ pulp were dense and the surface was covered by fine fibers (Fig. 2 b). From the cross section, the fibers of untreated paper were also clearly visible (Fig. 2 d). After gelation (Fig.2 e), the boundary between fibers was blurred. However, the frame of membranes was distinct. It indicated that the gelation occurred on the surface of fibers. In the crosssectional direction, it can be clearly observed that the membranes had a multilayer structure, which was induced by papermaking. This structure played an indispensable function in oil-water separation and the multilayer barrier structure was conducive to the realization of oil-water separation.

\subsection{The pore diameters distribution diagram}


Pulp refining was employed to produce fine fibers to fill the large pores on paper. Mercury intrusion method was used to analyze the pore diameters distribution diagram of paper with different beating degrees. The permeable pores were mainly distributed between $500 \mathrm{~nm}$ and $10000 \mathrm{~nm}$ (Fig. $3 \mathrm{a}, \mathrm{b}$ ). The larger pores were caused by the uneven surface (Fig. $3 \mathrm{e}, \mathrm{f}, \mathrm{g}$ ). The pore diameter and porosity of paper decreased with the increased of beating degrees. The gelation of paper could improve the porosity of paper-based membrane, but the pore diameter was almost no change (Table.1). it indicated the fine fibers was consumed partially by gelation process. To explore the separation efficiency and flux of paper and paper-based membranes. The reduced porosity and pore diameters improved the separation efficiencies of paper and membranes, but the flux was decreased. When the beating reached $35^{\circ} \mathrm{SR}$, the improvement of beating degree would only affect the flux, and the separation efficiency would remain above $98.5 \%$ (Fig.3 c, d). The separation efficiency was showed in Table.S1. The subsequent investigations of paperbased membranes were based on $35^{\circ} \mathrm{SR}$.

Table.1 Average pore diameters and porosity of paper substrates at different beating

\begin{tabular}{ccc}
\multicolumn{3}{c}{ degrees } \\
\hline Beating degrees $\left({ }^{\circ} \mathrm{SR}\right)$ & Average pore diameters $(\mu \mathrm{m})$ & Porosity $\%$ 口 \\
\hline $20^{\circ} \mathrm{SR}$ & 16.74 & $69.17 \%$ \\
$25^{\circ} \mathrm{SR}$ & 16.08 & $65.81 \%$ \\
\hline $30^{\circ} \mathrm{SR}$ & 14.59 & $64.17 \%$ \\
\hline $35^{\circ} \mathrm{SR}$ & 12.88 & $59.25 \%$ \\
\hline $40^{\circ} \mathrm{SR}$ & 10.87 & $59.10 \%$ \\
\hline $45^{\circ} \mathrm{SR}$ & 9.76 & $56.88 \%$ \\
\hline $50^{\circ} \mathrm{SR}$ & 8.59 & $56.32 \%$ \\
\hline $35^{\circ} \mathrm{SR}$ membrane & 12.93 & $62.65 \%$ \\
\hline
\end{tabular}

\subsection{Properties of membranes}

During the regeneration process, different regeneration solutions were discussed, including water $(\mathrm{Li}$, Zhang \& Xu, 2012)『ethanol(Li et al., 2020) $₫ 5 \mathrm{wt} \% \mathrm{Na}_{2} \mathrm{SO}_{4}$ solution(Mao, Zhou, Cai \& Zhang, 2006) and $2 w t \% / 4 w t \% / 6 w t \%$ acetic acid solution(Yang, Ma, Tang \& Feng, 2018), and the membranes regenerated using these solutions were named as $M-1, M-2, M-3, M-4, M-5, M-6$, respectively. $M-0$ is the paper substrate.

\subsubsection{Wetting behaviors of membranes}

The wettability of membranes (1-6) was showed in Fig.4. The water wetting behaviors of membranes (Fig.4 b) were characterized in air, while the oil wetting behaviors (Fig.4 a) were characterized under water. As the results showed that the water contact angels of membranes were nearly $0^{\circ}$ while the oil contact angels were all greater than $150^{\circ}$. All membranes showed a superhydrophilicity and underwater superoleophobicity properties (Ge, Zong, Jin, Yu \& Ding, 2018). 
The contact processes between oil-water droplets and the surface of membrane were photographed using a high-speed camera to further confirm the wettability of membranes. As shown in Fig.4 (c), the membranes could absorb water quickly after placing a drop of water on its surface in air in 1.53s and the water contact angel was nearly $0^{\circ}$, confirming the superhydrophilicity properties of membranes. Meanwhile, when the membranes were under water (Fig.4 d), the membranes were hardly penetrated by oil droplets, even if the oil droplets were driven down by the needle during the contact process. And after the needle was lifted up, the oil droplets could be easily lifted without deformation, indicating the low oil adhesion of membranes (He, Duan, Chen, Liu, Yang \& Wang, 2015). After absorbing water, the membranes would not be invaded by oil, even if it was not under water (Fig. S1). It confirmed that the hydration layer can effectively block the invasion of oil droplets.

\subsubsection{Oil-in-water emulsion separation}

The oil-water separation efficiency of membranes was evaluated by the UV-vis spectra (Lu \& Yuan, 2017). The separation efficiencies of the membranes (1-6) were shown in Fig.5 (a, b, c), representing the separation efficiency of the three separation times in turn, and the paper substrate ( $\left.35^{\circ} \mathrm{SR}\right)$ was control group. At the first separation process, all of the membranes separation efficiency were $\mathbb{9 8 . 5 \%}$. In addition, the numbers were throughout higher than $98 \%$ after three times separations. This confirmed that the regeneration solutions could only affect the flux of the membranes.

The stability was essential for membrane to separate oil-in-water emulsions successfully. The stability of paper-based membranes was better than paper substrates (Fig. $5 \mathrm{c}$, d). The separation efficiency of membranes could maintain more than $95 \%$ after 20 separation times while the paper substrates could only separate $5 \sim 6$ times. And the flux of membranes could remain within a certain range.

By comparing the emulsion and filtrate under the polarizing microscope (Fig.5 b), we could find that the feed emulsion was full of toluene droplets while the toluene droplets disappeared in the filtrate, and the milky emulsion was transformed into transparent liquid. This could also be confirmed by UV-vis spectrum (Fig.S3).

\subsection{4 the strength of membranes}

Throughout the gelation, the wet strength of paper-based membranes was remarkable improved. From Fig.6 (a) and (b), the dry strength of membranes had no significant change, while the wet strength had a substantial increase. Compared with paper substrate, the wet tensile index of membranes had been improved about 15 to 18 times, the wet bursting strength index about 4 times. The enhancement of its strength was mainly owing to the stability of the internal fiber structure of the material after gelation and the stability of gel in water. In order to compare the wet strength of the membranes and paper intuitively, a $1 \mathrm{Kg}$ weight was placed on the wet paper and film (Fig.6 C), the paper was crushed instantly, and the membrane was intact (Video S1, S2). And the results of FT-IR spectra (Fig.S4) and WAXD (Fig.S5) could further confirm that the membranes were self-enhancement. 


\subsection{Separation mechanism}

The hypothetical principles schematic was represented in Fig.7. The membranes can quickly absorb and retain water to form a hydrated layer on the membranes when the pulp was refined to a degree. This is due to the fibrillation of pulp caused by pulp refining, resulting in the compact fiber structure of the membrane. And the water retention value (WRV) of pulps was another important evidence of the hydration layer. After refining, the WRV of pulps were both higher than unrefined pulp before and after gelation (Table.S3). The role of the hydration layer is speculated as follows. The oil droplets will collide with the water hydration layer under gravity, and the emulsion will be partial break. The exposed oil droplets will be intercepted by the water hydration layer (Koh, Lim, Zhou, Zhang, Ding \& He, 2019). The water in the emulsion will be absorbed continuously by the membrane and separated under gravity, and a water replacement is formed in the membrane. With the accumulation and aggregation of oil droplets, the contact of oil droplets will be rise, and the emulsion will be break. The demulsified oil droplets will gather with the oil droplets in contact with them to form larger oil droplets. The big oil droplets will float up. By contrary, the membrane without pulp refining will not form a continuous water hydration layer. And the oil droplets will easily pass through the surface of the membrane. Therefore, pulp refining can effectively improve the oil drop barrier performance of the membranes.

\section{Conclusions}

In summary, we have fabricated a cellulosic membrane by papermaking and in-situ gelation. The membranes show a superhydrophilicity and underwater superoleophobicity. Meanwhile, the remarkable increase in wet strength by in-situ gelation is in line with the expected use of the membranes. The flux of membranes can be adjusted by pulp refining and regeneration conditions, The reduction of pore size and the improvement of water retention performance are considered to be the key. The separation efficiencies for oil-in-water emulsions are $\$ 98.5 \%$. The prepared materials are all composed of cellulose, it's convenient in use and waste disposal. Besides, the preparation of this membrane is combined with the papermaking process to provide a possibility for large-scale preparation in the future.

\section{Declarations}

\section{Author statement}

Dengcheng Gao: Conceptualization, Methodology, Investigation, Data Curation, Writing - original draft. Xiao Zhang: Methodology, Investigation, Data Curation. Shuying Wu: Methodology, Investigation, Data Curation. Yucheng Feng: Conceptualization, Supervision, Writing - review \& editing. Fei Yang: Conceptualization, Supervision, Writing - review \& editing.

\section{Acknowledgements}

The authors are grateful for the support from the Natural Science Foundation of Guangdong Province, China (2021A1515011263). 


\section{Conflicts of interest}

There are no conflicts to declare.

\section{References}

1. Afra, E., Yousefi, H., Hadilam, M. M., \& Nishino, T. (2013). Comparative effect of mechanical beating and nanofibrillation of cellulose on paper properties made from bagasse and softwood pulps. CARBOHYDRATE POLYMERS, 97(2), 725-730.

2. Ahmad, A. L., Majid, M. A., \& Ooi, B. S. (2011). Functionalized PSf/SiO2 nanocomposite membrane for oil-in-water emulsion separation. DESALINATION, 268(1-3), 266-269.

3. Anis, S. F., Lalia, B. S., Lesimple, A., Hashaikeh, R., \& Hilal, N. (2021). Superhydrophilic and underwater superoleophobic nano zeolite membranes for efficient oil-in-water nanoemulsion separation. Journal of Water Process Engineering, 40, 101802.

4. Ao, C., Hu, R., Zhao, J., Zhang, X., Li, Q., Xia, T., Zhang, W., \& Lu, C. (2018). Reusable, salt-tolerant and superhydrophilic cellulose hydrogel-coated mesh for efficient gravity-driven oil/water separation. CHEMICAL ENGINEERING JOURNAL, 338, 271-277.

5. Ao, C., Zhao, J., Li, Q., Zhang, J., Huang, B., Wang, Q., Gai, J., Chen, Z., Zhang, W., \& Lu, C. (2020). Biodegradable all-cellulose composite membranes for simultaneous oil/water separation and dye removal from water. CARBOHYDRATE POLYMERS, 250, 116872.

6. Banavath, H. N., Bhardwaj, N. K., \& Ray, A. K. (2011). A comparative study of the effect of refining on charge of various pulps. BIORESOURCE TECHNOLOGY, 102(6), 4544-4551.

7. Cai, Q., Zhu, Z., Chen, B., \& Zhang, B. (2019). Oil-in-water emulsion breaking marine bacteria for demulsifying oily wastewater. WATER RESEARCH, 149, 292-301.

8. Chakrabarty, B., Ghoshal, A. K., \& Purkait, M. K. (2008). Ultrafiltration of stable oil-in-water emulsion by polysulfone membrane. JOURNAL OF MEMBRANE SCIENCE, 325(1), 427-437.

9. Chen, D., Zhu, H., Yang, S., Li, N., Xu, Q., Li, H., He, J., \& Lu, J. (2016). Micro-Nanocomposites in Environmental Management. ADVANCED MATERIALS, 28(47), 10443-10458.

10. Chu, Z., Feng, Y., \& Seeger, S. (2015). Oil/Water Separation with Selective Superantiwetting/Superwetting Surface Materials. Angewandte Chemie International Edition, 54(8), 2328-2338.

11. Dalton, T., \& Jin, D. (2010). Extent and frequency of vessel oil spills in US marine protected areas. MARINE POLLUTION BULLETIN, 60(11), 1939-1945.

12. Feng, X. J., \& Jiang, L. (2006). Design and Creation of Superwetting/Antiwetting Surfaces. ADVANCED MATERIALS, 18(23), 3063-3078.

13. Ge, J., Zong, D., Jin, Q., Yu, J., \& Ding, B. (2018). Biomimetic and Superwettable Nanofibrous Skins for Highly Efficient Separation of Oil-in-Water Emulsions. ADVANCED FUNCTIONAL MATERIALS, 28(10), 1705051. 
14. Gharehkhani, S., Sadeghinezhad, E., Kazi, S. N., Yarmand, H., Badarudin, A., Safaei, M. R., \& Zubir, M. N. M. (2015). Basic effects of pulp refining on fiber properties-A review. CARBOHYDRATE POLYMERS, 115, 785-803.

15. Gu, J., Xiao, P., Chen, P., Zhang, L., Wang, H., Dai, L., Song, L., Huang, Y., Zhang, J., \& Chen, T. (2017). Functionalization of Biodegradable PLA Nonwoven Fabric as Superoleophilic and Superhydrophobic Material for Efficient Oil Absorption and Oil/Water Separation. ACS Applied Materials \& Interfaces, $9(7), 5968-5973$.

16. He, K., Duan, H., Chen, G. Y., Liu, X., Yang, W., \& Wang, D. (2015). Cleaning of Oil Fouling with Water Enabled by Zwitterionic Polyelectrolyte Coatings: Overcoming the Imperative Challenge of Oil-Water Separation Membranes. ACS Nano, 9(9), 9188-9198.

17. Hou, Q., Yang, B., Liu, W., Liu, H., Hong, Y., \& Zhang, R. (2011). Co-refining of wheat straw pulp and hardwood kraft pulp. CARBOHYDRATE POLYMERS, 86(1), 255-259.

18. Hu, Y., Wei, J., Liang, Y., Zhang, H., Zhang, X., Shen, W., \& Wang, H. (2016). Zeolitic Imidazolate Framework/Graphene Oxide Hybrid Nanosheets as Seeds for the Growth of Ultrathin Molecular Sieving Membranes. Angewandte Chemie International Edition, 55(6), 2048-2052.

19. Huang, F., Li, Q., Ji, G., Tu, J., Ding, N., Qu, Q., \& Liu, G. (2021). Oil/water separation using a lauric acidmodified, superhydrophobic cellulose composite membrane. MATERIALS CHEMISTRY AND PHYSICS, $266,124493$.

20. Ivshina, I. B., Kuyukina, M. S., Krivoruchko, A. V., Elkin, A. A., Makarov, S. O., Cunningham, C. J., Peshkur, T. A., Atlas, R. M., \& Philp, J. C. (2015). Oil spill problems and sustainable response strategies through new technologies. Environmental science-processes \& impacts, 17(7), 121-1219.

21. Koh, J. J., Lim, G. J. H., Zhou, X., Zhang, X., Ding, J., \& He, C. (2019). 3D-Printed Anti-Fouling Cellulose Mesh for Highly Efficient Oil/Water Separation Applications. ACS Applied Materials \& Interfaces, 11(14), 13787-13795.

22. Li, F., Wang, Z., Huang, S., Pan, Y., \& Zhao, X. (2018). Flexible, Durable, and Unconditioned Superoleophobic/Superhydrophilic Surfaces for Controllable Transport and Oil-Water Separation. ADVANCED FUNCTIONAL MATERIALS, 28(20), 1706867.

23. Li, H., Kruteva, M., Mystek, K., Dulle, M., Ji, W., Pettersson, T., \& Wågberg, L. (2020). Macro- and Microstructural Evolution during Drying of Regenerated Cellulose Beads. ACS Nano, 14(6), 67746784.

24. Li, J., Zhou, Y., \& Luo, Z. (2017). Mussel-inspired V-shaped copolymer coating for intelligent oil/water separation. CHEMICAL ENGINEERING JOURNAL, 322, 693-701.

25. Li, R., Zhang, L., \& Xu, M. (2012). Novel regenerated cellulose films prepared by coagulating with water: Structure and properties. CARBOHYDRATE POLYMERS, 87(1), 95-100.

26. Lin, L., Liu, M., Chen, L., Chen, P., Ma, J., Han, D., \& Jiang, L. (2010). Bio-Inspired Hierarchical Macromolecule-Nanoclay Hydrogels for Robust Underwater Superoleophobicity. ADVANCED MATERIALS, 22(43), 4826-4830. 
27. Lu, Y., \& Yuan, W. (2017). Superhydrophobic/Superoleophilic and Reinforced Ethyl Cellulose Sponges for Oil/Water Separation: Synergistic Strategies of Cross-linking, Carbon Nanotube Composite, and Nanosilica Modification. ACS Applied Materials \& Interfaces, 9(34), 29167-29176.

28. M. Cheryana, N. R. (1998).

Membraneprocessingofoilystreams.Wastewatertreatmentandwastereduction. JOURNAL OF MEMBRANE SCIENCE.

29. Mao, Y., Zhou, J., Cai, J., \& Zhang, L. (2006). Effects of coagulants on porous structure of membranes prepared from cellulose in $\mathrm{NaOH} /$ urea aqueous solution. JOURNAL OF MEMBRANE SCIENCE, 279(12), 246-255.

30. Moura, M. J., Ferreira, P. J., \& Figueiredo, M. M. (2005). Mercury intrusion porosimetry in pulp and paper technology. POWDER TECHNOLOGY, 160(2), 61-66.

31. Nishino, T., Matsuda, I., \& Hirao, K. (2004). All-Cellulose Composite. MACROMOLECULES, 37(20), 7683-7687.

32. Piltonen, P., Hildebrandt, N. C., Westerlind, B., Valkama, J., Tervahartiala, T., \& Illikainen, M. (2016). Green and efficient method for preparing all-cellulose composites with $\mathrm{NaOH} /$ urea solvent. COMPOSITES SCIENCE AND TECHNOLOGY, 135, 153-158.

33. Rana, D., \& Matsuura, T. (2010). Surface Modifications for Antifouling Membranes. CHEMICAL REVIEWS, 110(4), 2448-2471.

34. Sehaqui, H., Zhou, Q., Ikkala, O., \& Berglund, L. A. (2011). Strong and Tough Cellulose Nanopaper with High Specific Surface Area and Porosity. BIOMACROMOLECULES, 12(10), 3638-3644.

35. Shibata, M., Teramoto, N., Nakamura, T., \& Saitoh, Y. (2013). All-cellulose and all-wood composites by partial dissolution of cotton fabric and wood in ionic liquid. CARBOHYDRATE POLYMERS, 98(2), 1532-1539.

36. Wang, B., Liang, W., Guo, Z., \& Liu, W. (2014). Biomimetic super-lyophobic and super-lyophilic materials applied for oil/water separation: a new strategy beyond nature. CHEMICAL SOCIETY REVIEWS, 44(1), 336-361.

37. Xi, J., Lou, Y., Jiang, S., Fang, G., \& Wu, W. (2021). Robust paper-based materials for efficient oilwater emulsion separation. CELLULOSE, 28(16), 10565-10578.

38. Xie, A., Cui, J., Chen, Y., Lang, J., Li, C., Yan, Y., \& Dai, J. (2019). One-step facile fabrication of sustainable cellulose membrane with superhydrophobicity via a sol-gel strategy for efficient oil/water separation. Surface and Coatings Technology, 361, 19-26.

39. Xu, T., Gao, Z., Jia, Y., Miao, X., Zhu, X., Lu, J., Wang, B., Song, Y., Ren, G., \& Li, X. (2021).

Superhydrophobic corn straw as a versatile platform for oil/water separation. CELLULOSE, 28(8), 4835-4846.

40. Yang, F., Ma, H., Tang, L., \& Feng, Y. (2018). Effect of Polyvinyl Alcohol Treatment on Mechanical Properties of Bamboo/Polylactic Acid Composites. BioResources, 13(2).

41. Yang, X., Sun, H., Pal, A., Bai, Y., \& Shao, L. (2018). Biomimetic Silicification on Membrane Surface for Highly Efficient Treatments of Both Oil-in-Water Emulsion and Protein Wastewater. ACS Applied 
Materials \& Interfaces, 10(35), 29982-29991.

42. Yang, X., Yan, L., Ma, J., Bai, Y., \& Shao, L. (2019). Bioadhesion-inspired surface engineering constructing robust, hydrophilic membranes for highly-efficient wastewater remediation. JOURNAL OF MEMBRANE SCIENCE, 591, 117353.

43. Yousefi, H., Faezipour, M., \& Nishino, T. (2011). All-cellulose composite and nanocomposite made from partially dissolved micro- and nano-fibers of canola straw. POLYMER JOURNAL(6).

44. Zhang, S., Jiang, G., Gao, S., Jin, H., Zhu, Y., Zhang, F., \& Jin, J. (2018). Cupric Phosphate NanosheetsWrapped Inorganic Membranes with Superhydrophilic and Outstanding Anticrude Oil-Fouling Property for Oil/Water Separation. ACS Nano, 12(1), 795-803.

45. Zhao, Y., Yang, X., Yan, L., Bai, Y., Li, S., Sorokin, P., \& Shao, L. (2021). Biomimetic nanoparticleengineered superwettable membranes for efficient oil/water separation. JOURNAL OF MEMBRANE SCIENCE, 618, 118525.

46. Zhu, Y., Wang, D., Jiang, L., \& Jin, J. (2014). Recent progress in developing advanced membranes for emulsified oil/water separation. NPG Asia Materials, 6(5), e101.

\section{Figures}

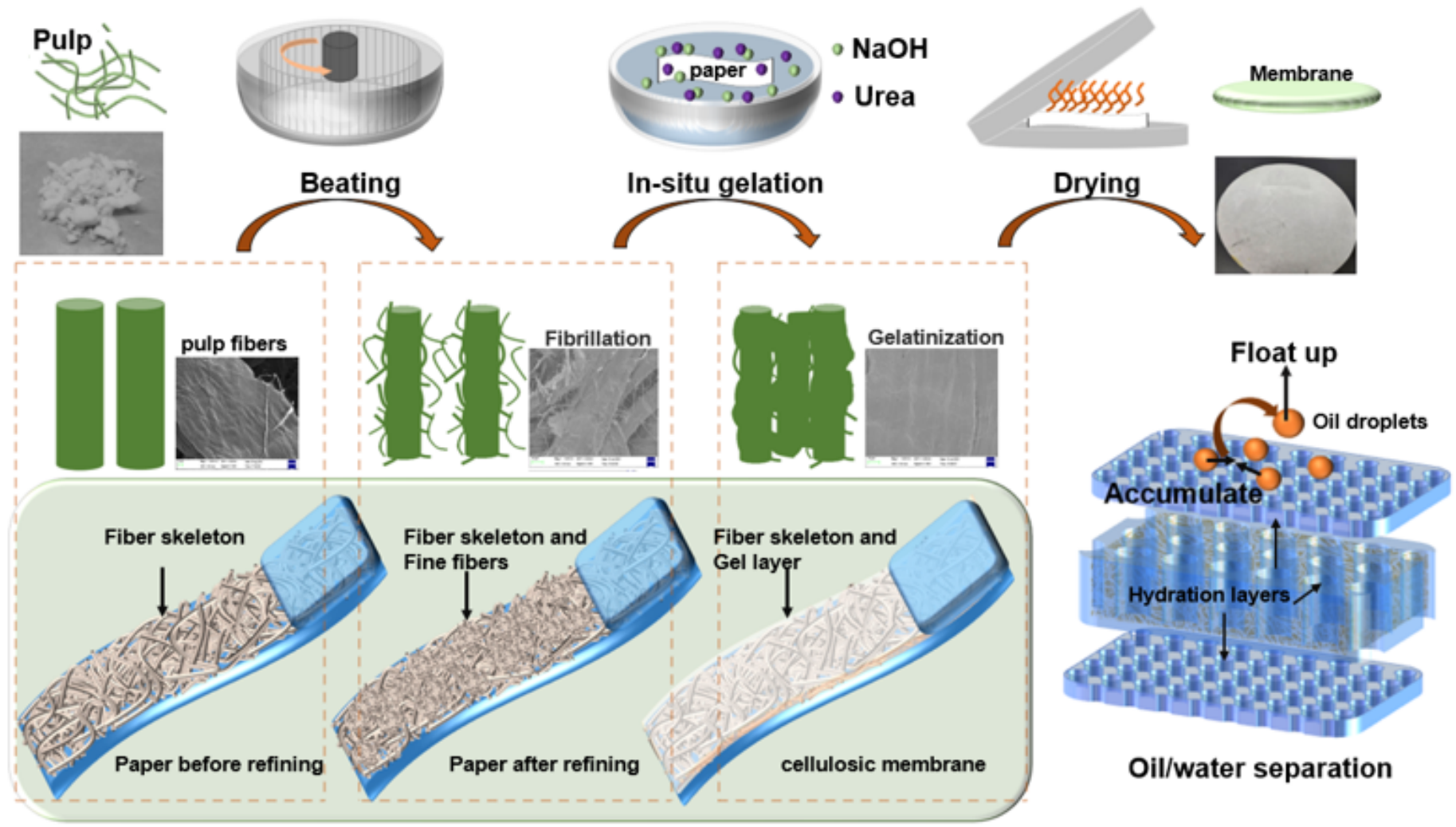

\section{Figure 1}

Schematic showing the preparation of membranes 

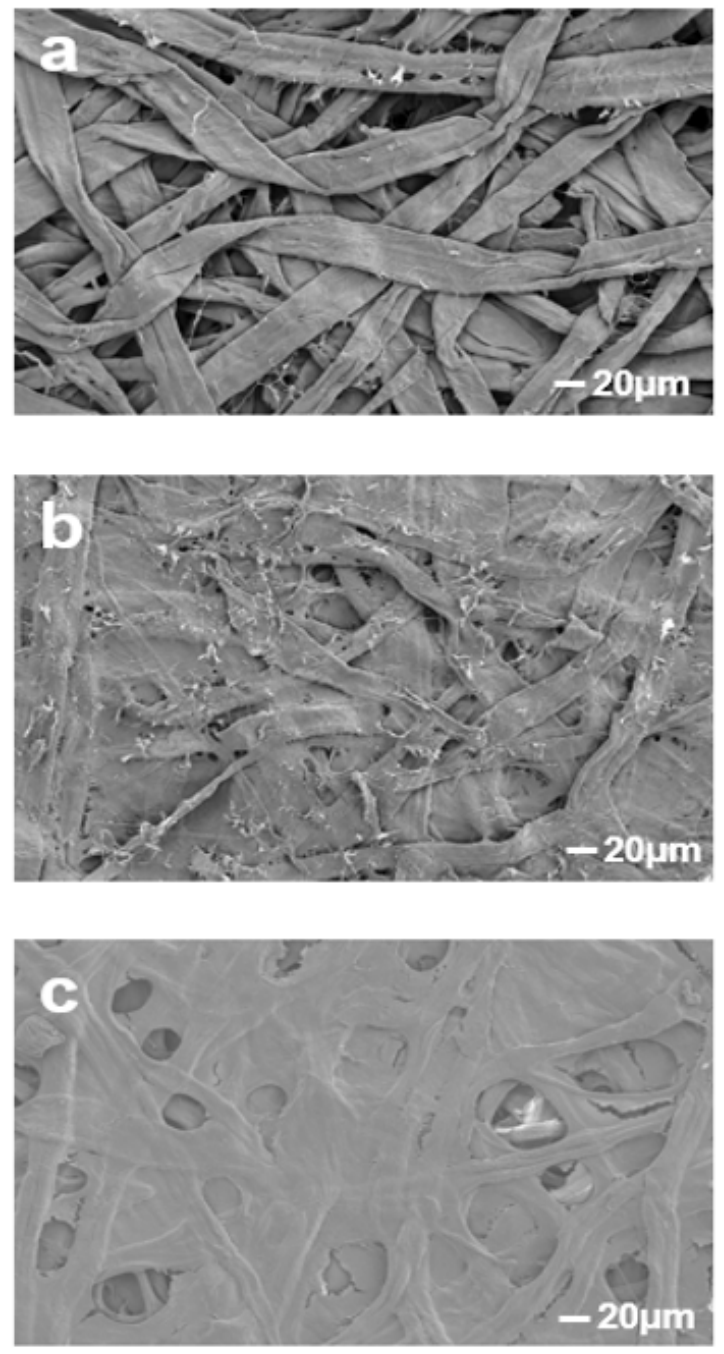
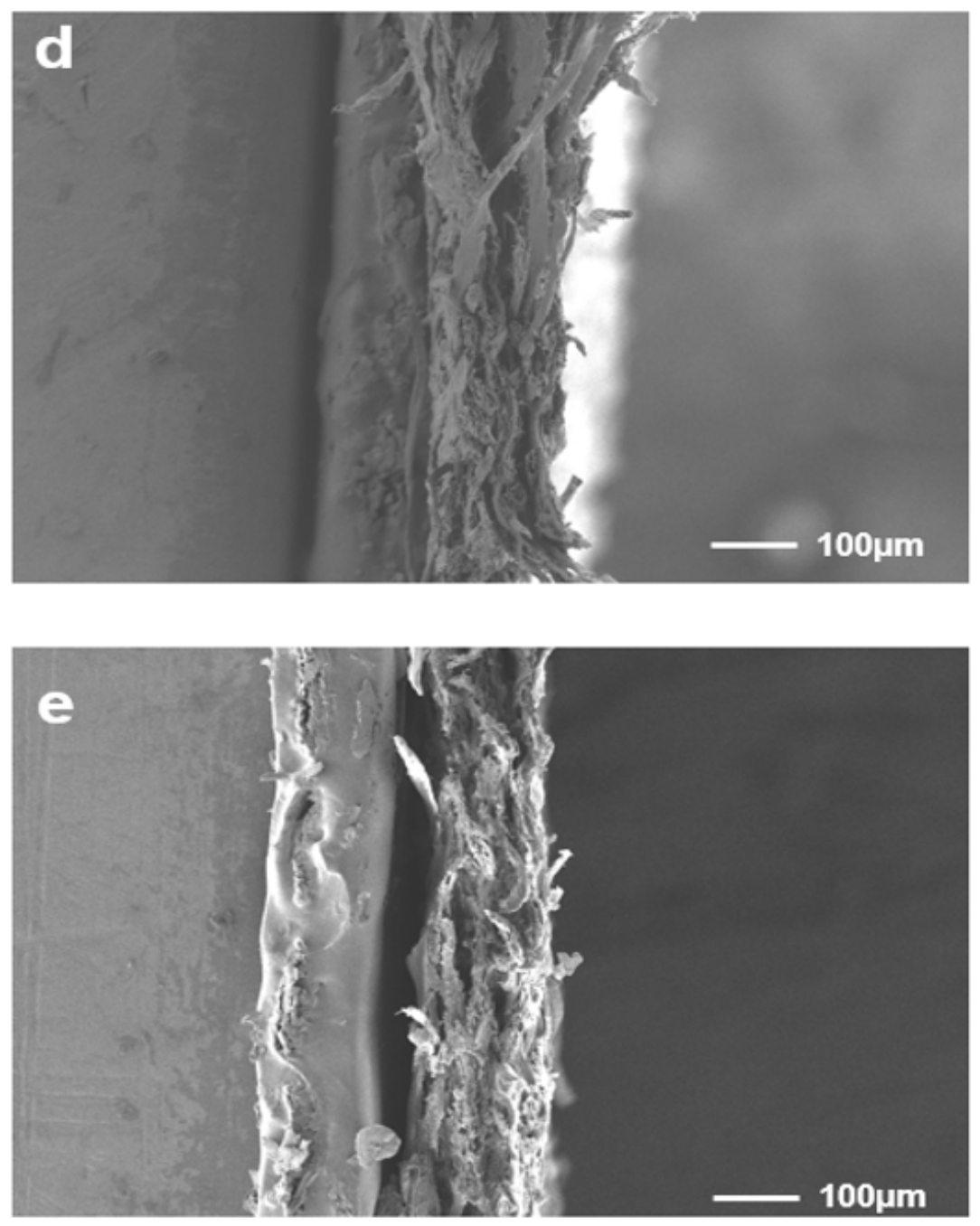

\section{Figure 2}

SEM micrographs of paper substrate and paper-based membrane: (a) paper substrate (10 ${ }^{\circ} \mathrm{SR}$ pulp); (b) paper substrate ( $35^{\circ} \mathrm{SR}$ pulp); (c) membranes ( $35^{\circ} \mathrm{SR}$ pulp); (d) the cross section of paper substrate (35 ${ }^{\circ} \mathrm{SR}$ pulp); (e) the cross section of membranes ( $35^{\circ} \mathrm{SR}$ pulp) 

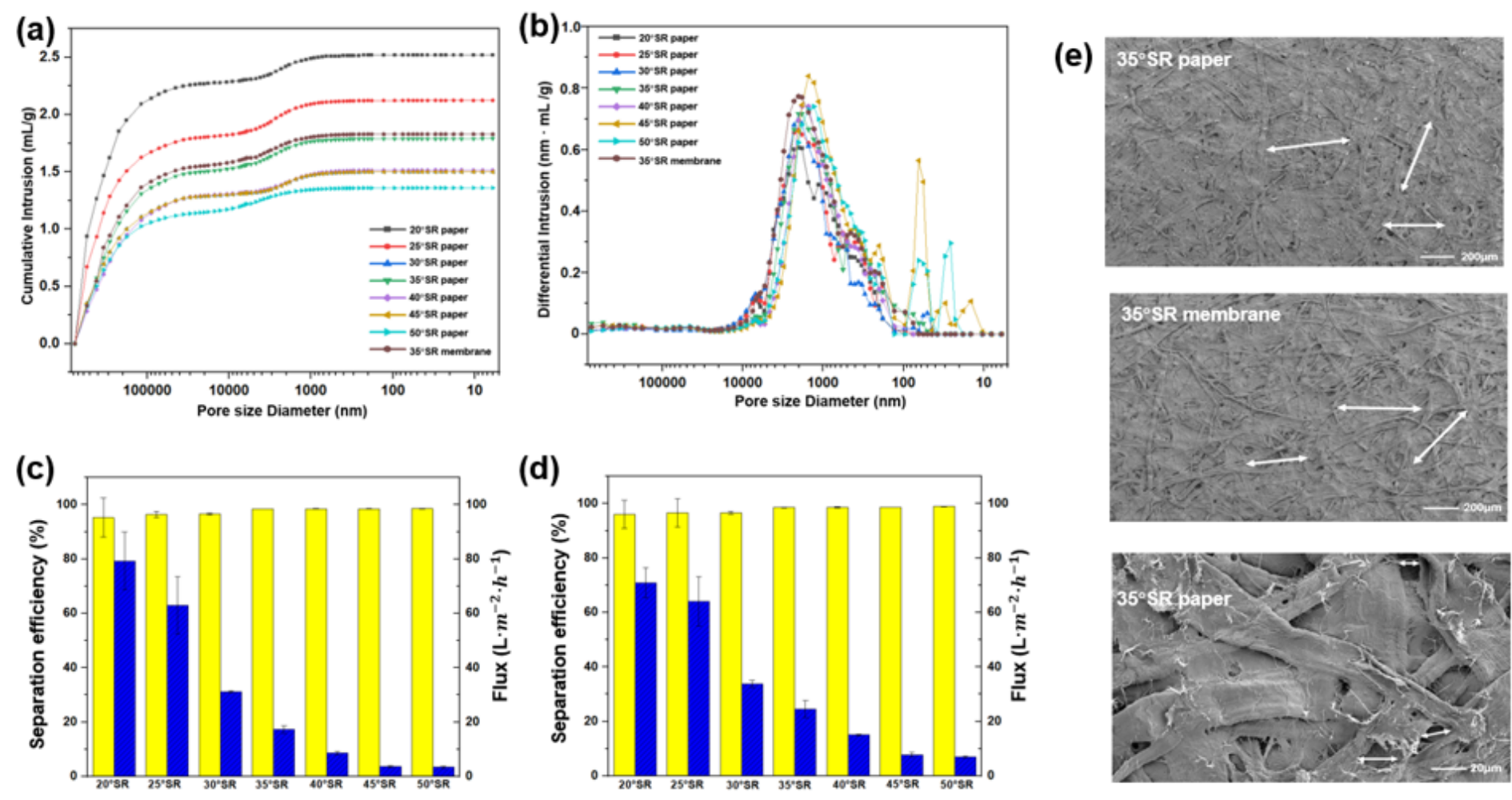

Figure 3

Curves of pore size and mercury injection increment: (a) the curves of cumulative intrusion and pore size; (b) the curves of differential intrusion and pore size; (c) the separation and flux of paper at different beating degrees; (d) the separation and flux of membranes (water regeneration) at different beating degrees; (e) the SEM images of paper and membrane at $35^{\circ} \mathrm{SR}$ 
(a)

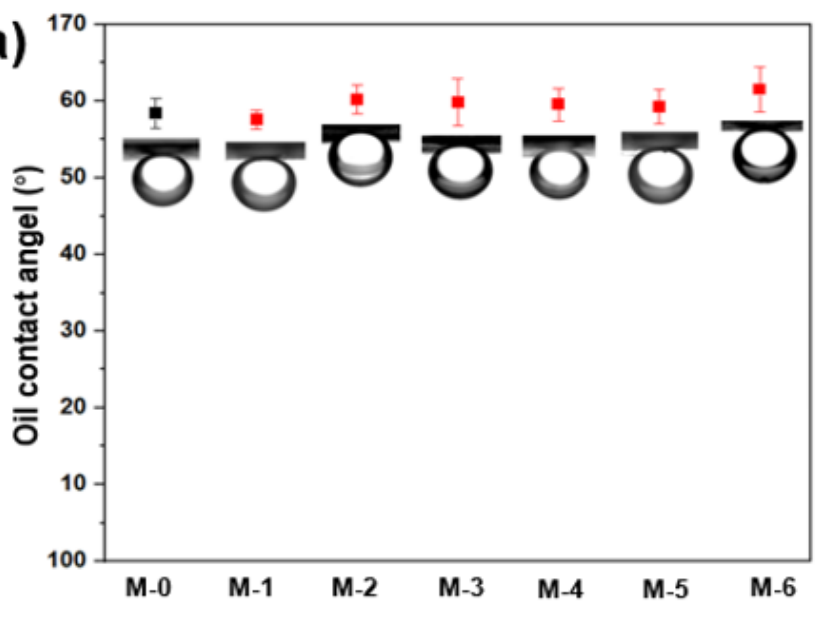

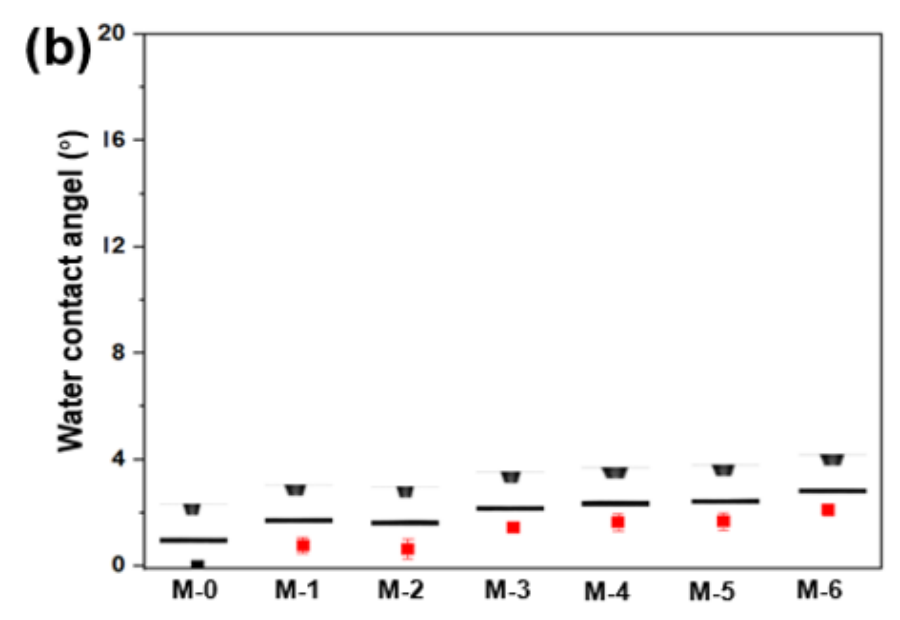

(c) Air

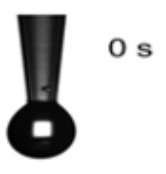

$0.08 \mathrm{~s}$

$0.15 \mathrm{~s}$

$0.44 \mathrm{~s}$

(d)
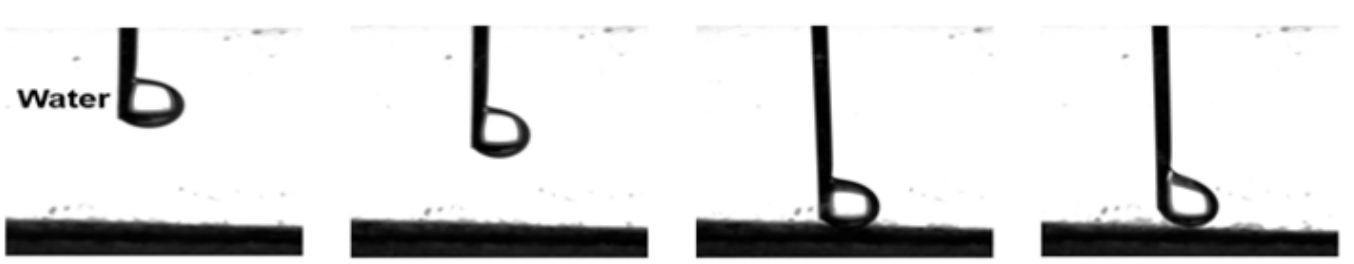

b

Figure 4

(a) The oil contact angels of membranes; (b) The water contact angels of membranes; (c) High-speed camera photo of water droplets on the membranes; (d) High-speed camera photo of oil droplets (1,2dichloroethane) on the membranes 
(a)

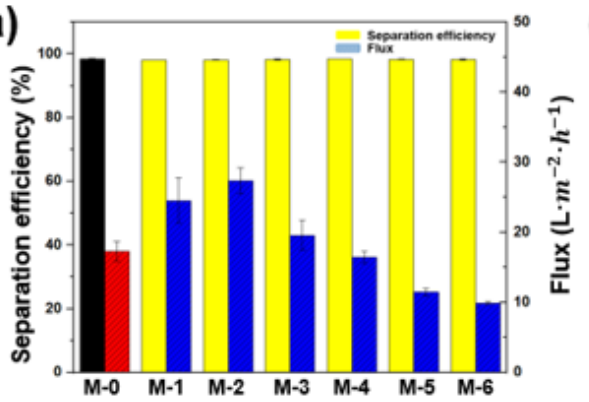

(b)

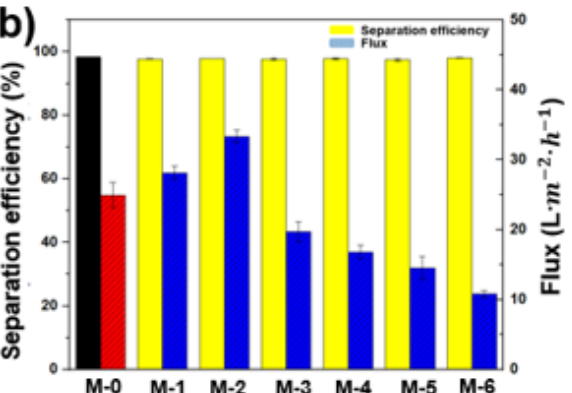

(d)

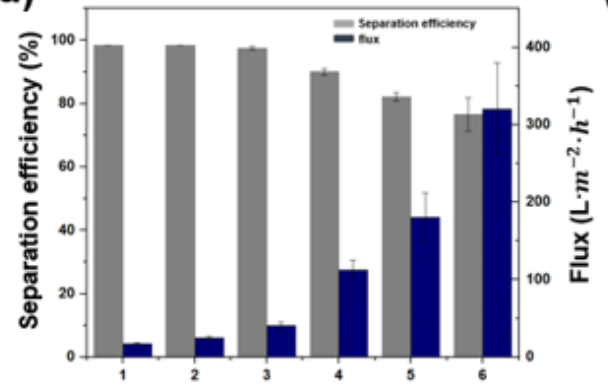

(e)

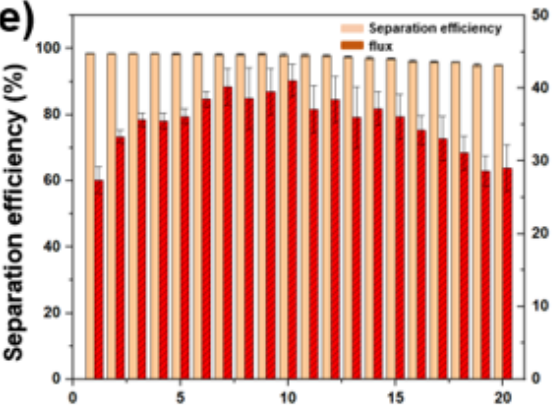

(c)

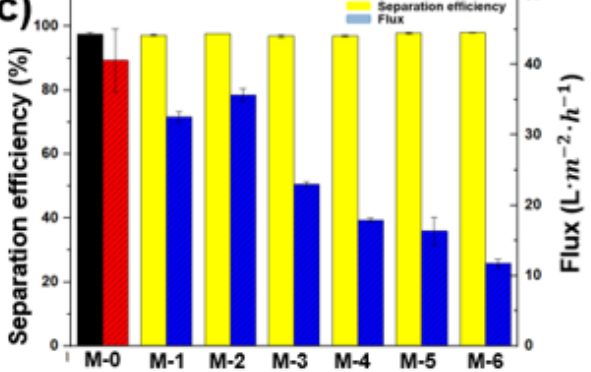

(f)

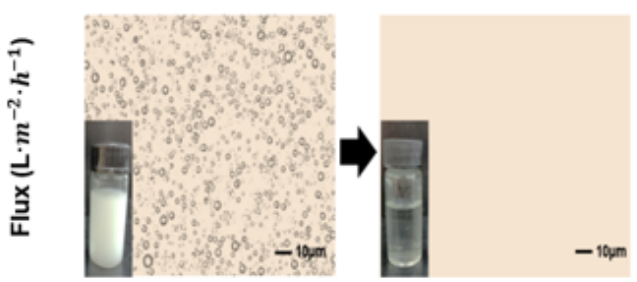

\section{Figure 5}

(a) the first separation efficiency of membranes; (b) the second separation efficiency of membranes; (c) the third separation efficiency of membranes; (d) the separation and flux of paper; (e) the separation efficiency of M-2; (f) the photograph and optical microscope images of the emulsion and the filtrate;

(a)
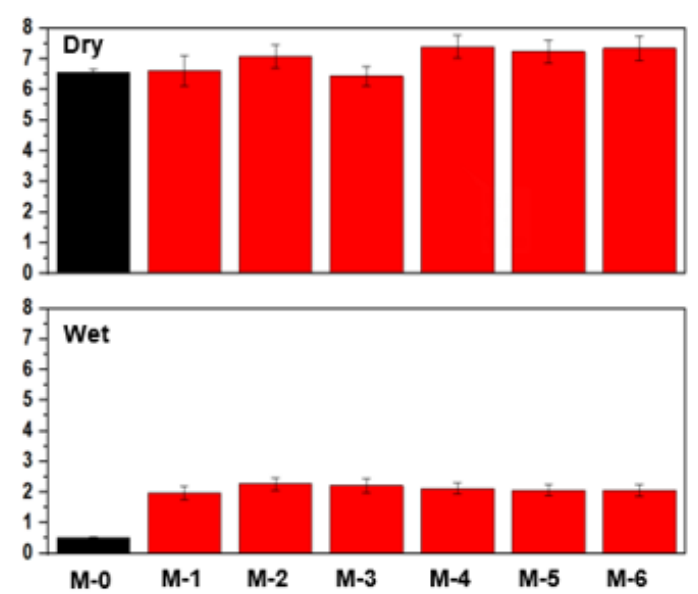

(b)

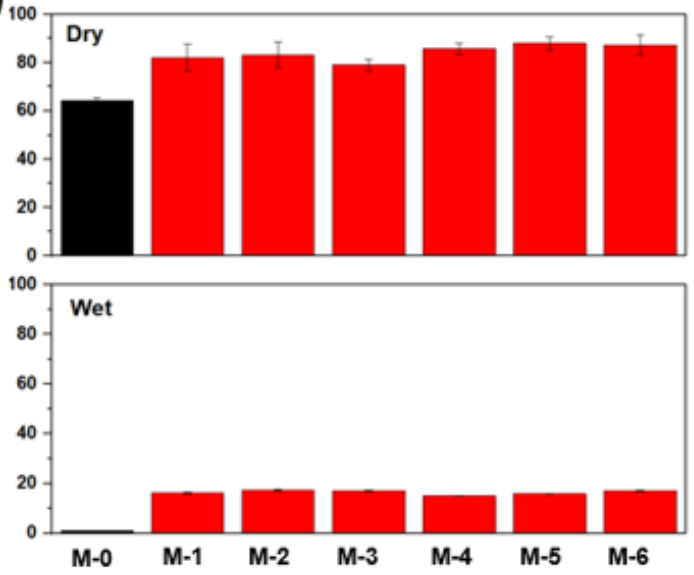

(c)
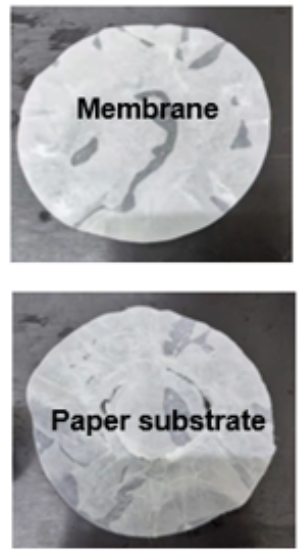

Figure 6

(a) the tensile index of membranes; (b) the burst index of membranes; (c) the photograph of compressive test under wet state 
Cellulose fibers

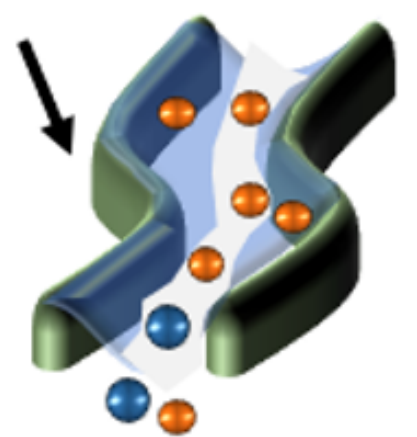

Fibers before refining

Oil droplets

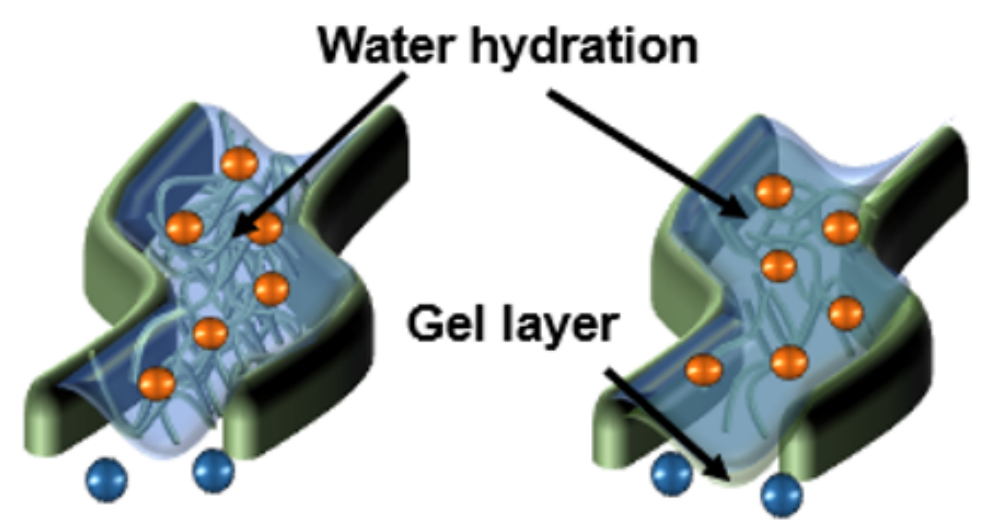

Fibers after refining

Fibers of membranes

Fine fibers

Figure 7

principles schematic showing the oil-water separation of membranes

\section{Supplementary Files}

This is a list of supplementary files associated with this preprint. Click to download.

- GraphicalAbstract.png

- SupplementaryMaterial.docx

- Videos1.mp4

- VideoS2.mp4 